\title{
Fusing AMSR-E and QuikSCAT imagery for improved sea ice recognition
}

\author{
Peter Yu, David A. Clausi, Senior Member, IEEE, Stephen E. L. Howell
}

\begin{abstract}
The benefits of augmenting AMSR-E image data with QuikSCAT image data for supervised sea ice classification in the Western Arctic region are investigated. Experiments compared the performance of a maximum likelihood classifier when used with the AMSR-E only data set against using the combined data. The preferred number of bands to use for classification was examined, as well as whether principal components analysis can be used to reduce the dimensionality of the data. The reliability of training data over time was also investigated. Adding QuikSCAT often improves classifier accuracy in a statistically significant manner and never decreased it significantly when a sufficient number of bands are used. Combining these data sets is beneficial for sea ice mapping. Using all available bands is recommended, data fusion with principal components analysis does not offer any benefit for these data and training data from a specific date remains reliable within 30 days.
\end{abstract}

Index Terms - data fusion, classification, scatterometer, passive microwave, Beaufort Sea, ice mapping, multisensor, principal component analysis

\section{INTRODUCTION}

$\mathbf{S}$ INCE the late 1970s, Arctic sea ice extent during the summertime has decreased by approximately $6 \%$ per decade [1]. Simulations by global climate models predict continued and potentially rapid decreases in sea ice [2]. Compared to observational records, climate model simulations may actually be far too conservative at predicting a summertime sea ice free Arctic [3] as witnessed by the rapid reduction of Arctic sea ice in 2007 [4]. These decreases in sea ice have raised many questions about the increased usage of Northwest Passage located in the middle of the Canadian Arctic as a viable shipping route. The mapping of sea ice is therefore an important task for understanding the global climate system and as well as for providing safe navigation, especially in Canadian Arctic waters.

In this work, the combination of data from the AMSRE passive microwave and SeaWinds/QuikSCAT (QuikSCAT) for supervised sea ice classification within Canadian Arctic waters is considered. Both sensors have been investigated for their use in providing sea ice type information in sea ice type segmentation algorithms. The QuikSCAT sensor has shown promising results for sea ice typing [5] [6], monitoring sea ice extent [7]-[9], sea ice edge detection [10] [11], sea ice melt detection [12] [13], and monitoring sea ice drift [14].

P. Yu and D.A. Clausi are members of the Vision and Image Processing (VIP) research group in the Department of Systems Design Engineering, University of Waterloo, Waterloo, ON, N2L 3G1 Canada.

S.E.L. Howell is with the Interdisciplinary Centre on Climate Change and the Department of Geography and Environmental Management, University of Waterloo, Waterloo, ON, N2L 3G1 Canada.
Passive microwave data from the SSM/I sensor (a predecessor of AMSR-E) has been used for ice typing [15] and AMSR-E data has been used in ice concentration computations that can distinguish between multiyear and first year ice in the Arctic and Antarctic [16] [17].

Recent work has found that combining passive microwave and scatterometer data is useful for sea ice classification and mapping. Remund et al. [18] used principal component analysis (PCA) to combine data from two scatterometer sensors (the NASA NSCAT and the European ERS-2 scatterometer) with data from the SSM/I satellite for use in an iterative maximum likelihood (ML) classifier. Other studies have combined SSM/I with QuikSCAT to classify new ice in Greenland [19] and to improve detection of one type of multiyear ice during the winter [20].

Although previous work has shown that both passive microwave and scatterometer data is useful regardless of whether they are used separately or together, little work has specifically combined AMSR-E and QuikSCAT data or compared the performance of using the multisensor data set against the individual data sets. These issues are examined here with a pattern recognition framework to generate quantitative results that can lead to developing an automated ice mapping system. In particular, the following research questions are posed:

1) Does adding QuikSCAT to AMSR-E provide a significant improvement in sea ice classification?

2) How does the number of preferred bands used in classification affect results?

3) Can principal component analysis (PCA) be used to reduce feature space dimensionality and improve the classification rate?

4) How reliable is the training data over time?

The answers to these questions will indicate whether the AMSR-E and QuikSCAT sensor combination should be investigated in more detail for use in sea ice classification. Questions 2 and 3 relate to the dimensionality of the combined data set, while Question 4 is relevant when considering the design of a database of training data to automatically classify new scenes.

\section{DATA}

Three sources of data were used in this study: AMSRE passive microwave image data, Seawinds/QuikSCAT scatterometer data and Canadian Ice Service (CIS) ice charts. Each data source is described in this section. 


\section{A. AMSR-E}

The AMSR-E sensor is a passive microwave radiometer on the Aqua satellite that measures the radiance of microwave radiation from the Earth's surface [21]. The AMSR-E sensor itself has many advantages that make it suitable for ice monitoring, including the ability to image without illumination (since the microwave radiation is emitted by the Earth's surface) and the ability to image through cloud cover [22]. The AMSR-E data used here is the daily average Level $3,12.5 \mathrm{~km}$ daily brightness temperature product [23]. This product has a polar stereographic projection and consists of 8 bands: 18 $\mathrm{GHz}, 23 \mathrm{GHz}, 36 \mathrm{GHz}$ and $89 \mathrm{GHz}$ in both horizontal and vertical polarizations.

\section{B. Seawinds/QuikSCAT (QuikSCAT)}

QuikSCAT data for the period September 2004 to August 2005 was obtained from the NASA Scatterometer Climate Record Pathfinder (SCP) project (see Acknowledgments for full attribution). The SeaWinds scatterometer on board the QuikSCAT satellite is a dual-polarized real aperture radar operating at $13.4 \mathrm{GHz}$ (Ku-band). QuikSCAT provides normalized cross-section backscatter values at fixed incident angles of $46^{\circ}(\mathrm{HH})$ and $54.1^{\circ}(\mathrm{VV})$ over a swath width of $1800 \mathrm{~km}$ with twice daily temporal resolution (i.e. daily ascending and descending passes). QuikSCAT data is available in two image products, eggs and slices, at Scatterometer Image Reconstruction (SIR) enhanced and non-enhanced grid resolution. The spatial resolution for the non-enhanced grid products is $11.125 \mathrm{~km}$ for slices and $22.25 \mathrm{~km}$ for eggs while the spatial resolution of SIR enhanced is $8-10 \mathrm{~km}$ and $4 \mathrm{~km}$ for eggs and slices, respectively [24].

The limitation with the higher resolution SIR products is that the resolution enhancement has a tendency to amplify noise [25]. Non-enhanced QuikSCAT data are produced using the "drop-in-the-bucket" technique, whereby the assigned backscatter value is the average of the measurements falling within the centre of the grid cell. This has the potential to contaminate backscatter returns with contributions from the shoreline, islands, and ice deformation features. Enhanced QuikSCAT data are produced from the SIR algorithm that was developed for multivariate scatterometer image reconstruction with noisy measurements by taking advantage of the spatial overlapping backscatter measurements taken at different times, thus increasing the sampling density in order to increase the spatial resolution [25], [26]. Early and Long [25] point out that there is a trade off between resolution enhancement and existing noise levels because high frequency noise will be amplified in the re-construction process. The SIR enhanced slice products further increase the spatial resolution $(4 \mathrm{~km})$ and the trade off between noise and resolution over sea ice is more strongly apparent [12]. For this study, we have chosen to use the combined ascending/descending pass egg products at both $\mathrm{HH}$ and VV polarizations to further increase the sampling density of the SIR data (i.e. maximizing spatial resolution) and minimize noise.

The projection of the AMSR-E data already matches the QuikSCAT egg data product so the only registration needed is
TABLE I

THE CIS STAGE OF DEVELOPMENT CODES MAPPED TO CLASS NAME USED IN THIS PAPER. STAGE OF DEVELOPMENT CODES WITH A PERIOD (.) AFTER THE NUMBER ARE DISTINCT ICE CLASSES FROM THOSE WITHOUT THE PERIOD.

\begin{tabular}{|c|c|}
\hline CIS Stage of Development Code & Class Name \\
\hline 1,2 & New Ice \\
$3,4,5$ & Young Ice \\
$6,7,4 ., 1 ., 8,9$ & First Year Ice \\
$7 ., 8 ., 9$. & Multiyear Ice \\
Open Water & Open Water \\
\hline
\end{tabular}

to scale the products to a common resolution, which is done via nearest neighbour interpolation to preserve the original data values.

\section{Canadian Ice Service Digital Database}

Sea ice concentration and type data was obtained from the Canadian Ice Service Digital Archive (CISDA) in order to provide ground truth for this study. These digital ice charts are topologically complete polygon ArcInfo Geographic Information Systems coverages and are available through the Canadian Ice Service (CIS). The ice charts define polygons which indicate the type and concentration of ice contained within the polygon region. The regional digital ice charts are derived weekly, from the integration of data from a variety of sources including surface observations and aerial and satellite reconnaissance (with the primary source being RADARSAT-1 since 1996), and represent the best estimate of ice conditions based on all available information at the time [27]. Agnew and Howell [28] compared the CIS digital ice charts to passive microwave concentration estimates from the National Aeronautics and Space Administration (NASA) Team algorithm [29]. They found the CIS digital ice charts to be a more accurate representation of ice coverage within the Canadian Arctic Archipelago compared to the NASA Team algorithm which can underestimate ice coverage between $-7.1 \%$ and $32.6 \%$ during the spring-melt and fall-freeze seasons.

The CIS ice charts are provided in a vector format that are then rasterized to the same projection as the image data before use. Additionally, the CIS defined ice types were aggregated into five classes for these experiments by grouping together similar CIS stage of development codes. Table I maps the CIS codes that were aggregated into each of the class names used in this study. The aggregation is done to ensure that there are sufficient ground truth samples for each class since individual stage of development codes may occur in only a few pixels in the image. Since the ice chart polygon regions can have stage of development codes that belong to more than one of the classes in Table I, only regions with $\geq 70 \%$ total concentration of one of the classes are considered ground truth to ensure that only representative samples are used. The exception to this is open water: only CIS regions that are explicitly marked as open water were used as ground truth samples.

\section{Study Period and Area}

The study period covers a full year from September 2004 to August 2005. The specific dates used here were chosen 
because the associated CIS ice charts provide sufficient ground truth samples for training $(\geq 100$ samples per class since there are 10 bands available in the AMSR-E and QuikSCAT combined data set, following the guideline of having at least 10 samples per band used in classification [30]) in the study area of the Western Arctic around the Beaufort sea.

\section{METHODS}

A maximum likelihood (ML) classifier was used for all experiments. The intent is to evaluate the data sources under a common classifier rather than designing the best classifier for the data. AMSR-E and QuikSCAT data have different units so the bands must be scaled before being used as features, ensuring that each feature is weighted fairly in distance calculations [31]. In a classification context, features refer to the properties of an object that help a classifier determine the object's class and they can be either direct measurements of the object or can be extracted by some operation on the measurements [31]. For the purposes of this study, a band of AMSR-E or QuikSCAT data is a feature as the bands are measurements of either the radiometric return or the backscatter at different locations in the scene and hence can be used by a classifier to help identify the type of ice that exists there. Since there are multiple bands in the data set, each spatial location has a feature vector, which consists of the values of all the bands at that location.

To minimize the distortion of the data, rather than scaling of all bands to a common range, the QuikSCAT dynamic range was linearly scaled to the full range of the AMSR-E data. Once the data are scaled, the combined feature set is created by stacking the data values from each AMSR-E band and the QuikSCAT bands into a ten dimensional feature vector at each spatial location. Except for tests in Section IV-D (explained later), each date was trained and validated independently with random selection of training and testing samples by consulting the CIS chart for that date.

The experiments required selecting feature (or band) subsets to use in classification. This refers to selecting a subset of the available bands to use in classification rather than all the bands. Feature selection methods attempt to select the best band subset of a given size based on some criterion $J(X)$, where $X$ is the candidate subset [32]. For example, choosing the best 3 bands to use in classification from the set of 10 bands in the AMSR-E and QuikSCAT combined data set could be accomplished by exhaustively forming all possible 3 band subsets and evaluating $J(X)$ for each, picking the subset that best satisfies the criteria. Exhaustive searching is not computationally feasible so various non-exhaustive methods have been devised [32]. A simple method is sequential forward search (SFS) [33], which takes as input the desired number of bands to use and starts by picking the one band that best satisfies the criterion. It then searches the remaining bands and finds the one that, together with the first selected band, forms the best two band subset that satisfies the criterion. The process continues until the desired number of bands to include in the subset is reached.

SFS is not an optimal feature selection algorithm and can choose suboptimal band subsets [34]. For the purposes of this study, however, SFS was preferred because differences in classification results between the combined data set and the individual data sets are easier to interpret with SFS. For example, in a comparison between the best 4 bands selected from the set of 8 AMSR-E bands and the best 4 bands selected from the set of 10 AMSR-E and QuikSCAT bands, SFS guarantees that if there is a difference in the results, the difference is directly due to the QuikSCAT band(s) being included in lieu of some AMSR-E band(s). This is because with the SFS algorithm, the same 4 AMSR-E bands selected from the AMSR-E only data set will be chosen from the combined data set if the QuikSCAT bands are not part of the best subset selected from the combined data set. More sophisticated feature selection methods do not have this property due to how they work: they might choose 4 AMSR-E bands from the AMSR-E only data set and then a different subset of 4 AMSR-E bands from the combined data set if the QuikSCAT bands are not part of the best subset. In this case, differences in the classification results will appear but these are differences between two different subsets of AMSR-E bands rather than differences between a subset of AMSR-E bands and a subset of AMSR-E and QuikSCAT bands. Since the accuracy difference between SFS and a more sophisticated method (Sequential Floating Forward Search [34]) was not statistically significant for the data used here, SFS was chosen to simplify interpretation.

As mentioned earlier, a criterion $J(X)$ needs to be evaluated in order to choose the best subset of bands to use. In this study, the transformed divergence [35], a measure of how separable two classes are based on the training data, between the two least separable classes is maximized.

The $\kappa$ (Kappa) coefficient and its confidence interval $\sigma$ [36] are used to evaluate classifier accuracy. $\kappa$ is a measure of overall classifier accuracy and is calculated from the error matrix of the classification result being evaluated [37]. $\kappa=1$ indicates that the classification result has perfect accuracy, $\kappa=0$ indicates that the result is no different than random assignment and $\kappa=-1$ indicates that the classification result is biased to be worse than random assignment. The $\kappa$ coeofficient is attractive for this study because the difference between two $\kappa$ values can be converted to a Z-value (a normalized score with zero mean and unit standard deviation, as seen in statistics), which can indicate whether the difference in accuracy between two classification results is statistically significant [37]. Z-values above 1.96 or below -1.96 can be considered statistically significant differences at the $95 \%$ level.

In order to answer Research Question 3, PCA is used as the data fusion method. Briefly, PCA involves using a transformation on the original feature vectors as follows [35]:

$$
\mathbf{y}=\mathbf{W} \mathbf{x}
$$

where $\mathbf{x}$ is the feature vector, $\mathbf{W}$ is the PCA transformation matrix and $\mathbf{y}$ is the PCA transformed feature vector. The matrix $\mathbf{W}$ is the matrix that diagonalizes the covariance matrix of the original data and is formed by writing the eigenvectors of the covariance matrix as rows [35].

Previous studies have used PCA as a data dimensionality reduction method by keeping only the top few principal 
component bands which contain most of the variance of the original data, such as in [18]. In this study, the use of principal component analysis is investigated by comparing classification results using a given number of principal component bands to classification results using the same number of original bands. This will determine whether PCA is a good method of data fusion for the AMSR-E and QuikSCAT data set.

\section{RESUlts}

\section{A. Question 1: Augmenting AMSR-E with QuikSCAT}

Table II shows Z-values which compare the classification using only AMSR-E data and using combined AMSR-E + QuikSCAT data at each band subset size. It compares the "best" (as chosen by SFS) $n$ bands chosen from the AMSR-E data set against the best $n$ bands of AMSR-E + QuikSCAT, where $n$ is the size of the band subset. The last two columns compare all eight AMSR-E with the nine or ten combined AMSR-E + QuikSCAT bands. The Z-values, as explained in Section III, indicate whether the difference between the AMSR-E only classification and the combined data set classification is statistically significant. For the most part, adding QuikSCAT either makes a statistically significant (at the 95\% level) improvement over AMSR-E alone or does not hurt the performance. A few rare cases show a significant decrease but these are for smaller band subset sizes, which (as shown later) perform worse than using all bands. The last column shows that when all ten bands from the combined data set are used, adding QuikSCAT improves the classification rate, with more than half showing a statistically significant increase. There is a very clear trend in July and August where AMSR-E + QuikSCAT shows no significant improvements over AMSRE alone. It appears that the benefits of augmenting AMSR-E with QuikSCAT data for ice classification are eroded during the summer.

Table III shows the $\kappa$ of the classification results for three different cases: using all eight AMSR-E, using both QuikSCAT bands and using all ten combined bands. This gives an idea of the classification performance via $\kappa$ and shows that the combined data set is better than either AMSR-E or QuikSCAT alone. The combined data set provides a slight increase in $\kappa$ over the AMSR-E only data set for July and August but, as discussed earlier, this increase is not large enough to be statistically significant. Also of note in Table III is that QuikSCAT alone cannot match the accuracy of AMSRE or the combined data set.

Table IV shows the percentage of the ground truth testing samples of each individual ice class that was correctly identified (the producer's classification accuracy) on each date, comparing the results from all 8 AMSR-E bands and all 10 combined bands. The AMSR-E + QuikSCAT data set shows improvements (in bold text) for all classes, presenting a strong case that QuikSCAT is a good complement to AMSRE. During the summer months of July and August, however, including QuikSCAT negatively influences the classification of multiyear ice and open water. This is consistent with previous results that indicate a weakness in the QuikSCAT data for these months. In these cases, the weaker classification results made the overall classification accuracy indistinguishable from a statistical significance standpoint from the AMSR-E only results.

Spatially, the AMSR-E 8 band and AMSR-E + QuikSCAT 10 band results are compared in Figure 1(a) for several dates. Both data sets allow correct identification of many pixels (gray) and incorrect identification of others (red). However, AMSR-E + QuikSCAT is more often correct (blue) than AMSR-E alone (yellow). The appearance of areas in yellow, indicating that AMSR-E alone was correct for those pixels, shows that the improvement due to QuikSCAT in some scenes (such as 20050620 and 20050815) is only a net gain in correctly identified pixels rather than an augmentation of the AMSR-E data set. Inspection of QuikSCAT images from the day before and the day after the date in question confirmed that the problem is a transient weather phenomenon in the yellow areas biasing the classification result towards the wrong class.

This weather effect is shown in Figure 2, which is a comparison of the 20050815 QuikSCAT image with the 20050816 image. QuikSCAT is susceptible to these transient weather changes because of its high sensitivity to melt and wind roughening of melt ponds on the surface causing large changes in backscatter. This may lead to false ice typing with QuikSCAT during freeze-thaw events and during the periods when melt ponds have formed. The sensitivity of QuikSCAT backscatter to wind-wave roughness means that wind roughened melt ponds will contribute even more to the overall backscatter. This wind roughness causes QuikSCAT backscatter intensities over both FYI and MYI to be high and similar. The high backscatter intensity can also be similar to an open water wind roughened surface, making it difficult to distinguish between FYI, MYI and open water. This appears to be the case in Figure 2 with 20050815 exhibiting strong backscatter intensities (i.e. a wind roughened melt pond surface) and 20050816 low backscatter intensities (i.e. calm weather conditions). The associated AMSR-E images are less affected by this problem because the physical temperature change due to the transient weather is not large, so the measured brightness temperature does not change much. When this weather induced problem does not exist, the improvements due to QuikSCAT are complementary to the AMSR-E only results (such as 20041004 and 20050829). These results indicate that a method is needed to exclude using QuikSCAT data when it is being disturbed by weather phenomena.

A large amount of incorrectly identified pixels (red) in the June and August results in Figure 1(a) correspond to multiyear ice being incorrectly classified. This can be seen by comparing the classification results in Figure 1(b) with the CIS ice charts in Figure 1(c). These dates are well into the melt season for 2005 [13] so the classification is likely being affected by the changing signature of the melting multiyear ice.

\section{B. Question 2: Number of preferred bands}

This section examines how the number of bands used affect classification with the AMSR-E + QuikSCAT data set. Table V shows Z-value comparisons between classifications using all 10 bands and those using subsets of 1 to 9 bands. The classifications using all 10 bands never have a statistically significant 
TABLE II

Z-VALUES COMPARING THE CLASSIFICATION RESULT USING THE SPECIFIED NUMBER OF BANDS CHOSEN FROM THE AMSR-E ONLY DATA SET AGAINST THE SPECIFIED NUMBER OF BANDS CHOSEN FROM THE COMBINED DATA SET. EACH VALUE COMPARES THE CLASSIFICATION PERFORMANCE OF THE BEST (AS CHOSEN BY THE SFS ALGORITHM) SET OF BANDS FROM EACH DATA SET, WITH POSITIVE VALUES INDICATING THAT THE COMBINED DATA SET HAS HIGHER ACCURACY AND NEGATIVE VALUES INDICATING THAT THE COMBINED DATA SET HAS LOWER ACCURACY. THE LAST TWO COLUMNS (9 VS 8 AND 10 VS 8) COMPARE THE RESULTS WITH 9 OR 10 BANDS CHOSEN FROM THE COMBINED DATA SET WITH THE RESULTS FROM ALL 8 AMSR-E BANDS.

\begin{tabular}{|c|r|r|r|r|r|r|r|r|r|r|}
\hline & \multicolumn{10}{|c|}{ Number of Bands Used For Classification } \\
\hline Dates & 1 & 2 & 3 & 4 & 5 & 6 & 7 & 8 & 9 vs 8 & 10 vs 8 \\
\hline 20040906 & -3.34 & -0.29 & -0.02 & 0.78 & 1.00 & 0.52 & -0.80 & 0.43 & 0.23 & 0.14 \\
20041004 & -7.31 & $\mathbf{4 . 5 7}$ & $\mathbf{2 . 7 9}$ & $\mathbf{6 . 9 1}$ & $\mathbf{4 . 1 6}$ & 1.50 & $\mathbf{3 . 0 3}$ & $\mathbf{4 . 4 5}$ & $\mathbf{4 . 8 2}$ & $\mathbf{3 . 9 2}$ \\
20041025 & $\mathbf{2 4 . 1 1}$ & $\mathbf{4 . 7 3}$ & 1.00 & $\mathbf{2 . 2 0}$ & $\mathbf{2 . 2 0}$ & 1.95 & 1.84 & 1.78 & $\mathbf{2 . 2 8}$ & $\mathbf{2 . 5 3}$ \\
20041108 & - & - & - & - & - & - & 1.59 & 1.71 & $\mathbf{2 . 4 6}$ & $\mathbf{3 . 6 2}$ \\
20050301 & - & -1.36 & 0.56 & 1.81 & 0.14 & 0.23 & 1.21 & 0.76 & 0.89 & 0.94 \\
20050601 & -0.73 & 0.51 & $\mathbf{2 . 0 5}$ & 0.36 & 0.26 & 0.80 & -1.52 & -0.06 & 1.65 & $\mathbf{2 . 5 7}$ \\
20050613 & - & 1.32 & $\mathbf{3 . 0 9}$ & 1.30 & $\mathbf{3 . 3 0}$ & $\mathbf{3 . 4 4}$ & $\mathbf{4 . 4 8}$ & $\mathbf{3 . 8 9}$ & $\mathbf{4 . 8 3}$ & $\mathbf{4 . 6 2}$ \\
20050620 & - & $\mathbf{9 . 2 0}$ & $\mathbf{1 0 . 0 5}$ & $\mathbf{1 0 . 3 3}$ & $\mathbf{1 2 . 8 9}$ & $\mathbf{1 0 . 0 8}$ & $\mathbf{1 0 . 9 0}$ & $\mathbf{1 1 . 0 4}$ & $\mathbf{1 1 . 7 9}$ & $\mathbf{1 2 . 0 4}$ \\
20050704 & $\mathbf{4 . 7 2}$ & $\mathbf{7 . 9 9}$ & 1.78 & $\mathbf{2 . 4 1}$ & $\mathbf{3 . 8 7}$ & $\mathbf{3 . 3 6}$ & $\mathbf{4 . 0 4}$ & $\mathbf{3 . 4 4}$ & $\mathbf{4 . 3 6}$ & $\mathbf{4 . 7 8}$ \\
20050711 & - & $\mathbf{3 . 1 5}$ & 0.36 & 1.20 & $\mathbf{3 . 4 1}$ & $\mathbf{3 . 7 8}$ & $\mathbf{4 . 1 2}$ & $\mathbf{3 . 7 7}$ & $\mathbf{3 . 9 9}$ & $\mathbf{4 . 9 1}$ \\
20050718 & - & - & - & - & - & -1.78 & -0.41 & -0.37 & -0.16 & 0.06 \\
20050725 & - & - & -1.79 & 1.80 & 0.15 & 1.55 & 1.02 & 0.56 & 0.46 & 0.51 \\
20050801 & - & - & -1.43 & 1.13 & 0.33 & -0.07 & -0.81 & -0.44 & -0.39 & 0.29 \\
20050808 & - & - & -0.75 & 1.50 & 0.50 & $\mathbf{2 . 0 3}$ & 0.41 & 1.87 & 1.91 & 1.63 \\
20050815 & - & - & -0.22 & -0.88 & 0.19 & -0.11 & -0.22 & 1.27 & 0.83 & 1.04 \\
20050822 & $\mathbf{4 . 2 9}$ & -1.64 & -1.07 & 1.67 & $\mathbf{2 . 1 3}$ & 0.46 & 0.24 & 1.14 & $\mathbf{2 . 1 0}$ & $\mathbf{2 . 5 0}$ \\
20050829 & - & - & - & 0.38 & $\mathbf{2 . 6 6}$ & 1.21 & $\mathbf{2 . 0 4}$ & $\mathbf{5 . 4 2}$ & $\mathbf{5 . 6 8}$ & $\mathbf{5 . 8 1}$ \\
\hline
\end{tabular}

Bold $=$ AMSR-E + QS has higher accuracy $(95 \%$ significance level $)$

Italic $=$ AMSR-E has higher accuracy (95\% significance level)

Plain $=$ Not significant; Dash $=$ QS not chosen by SFS .

TABLE III

$\kappa$ VALUES OBTAINED FOR THREE CASES OF CLASSIFICATION RESULTS: USING ALL 8 AMSR-E BANDS, USING BOTH QUIKSCAT BANDS AND USING ALL 10 AMSR-E + QUIKSCAT (10 BANDS) DATA SETS.

\begin{tabular}{|c|c|c|c|}
\hline & \multicolumn{3}{|c|}{$\kappa$} \\
\hline Dates & AMSR-E & QS & AMSR-E + QS \\
\hline 20040906 & 0.87 & 0.81 & 0.87 \\
20041004 & 0.78 & 0.67 & $\mathbf{0 . 8 2}$ \\
20041025 & 0.62 & 0.60 & $\mathbf{0 . 6 5}$ \\
20041108 & 0.57 & 0.56 & $\mathbf{0 . 6 4}$ \\
20050301 & 0.88 & 0.88 & 0.89 \\
20050601 & 0.63 & 0.49 & $\mathbf{0 . 6 7}$ \\
20050613 & 0.59 & 0.30 & $\mathbf{0 . 6 6}$ \\
20050620 & 0.40 & 0.44 & $\mathbf{0 . 6 0}$ \\
20050704 & 0.51 & 0.46 & $\mathbf{0 . 5 9}$ \\
20050711 & 0.55 & 0.46 & $\mathbf{0 . 6 4}$ \\
20050718 & 0.73 & 0.42 & 0.73 \\
20050725 & 0.68 & 0.43 & 0.69 \\
20050801 & 0.68 & 0.43 & 0.69 \\
20050808 & 0.69 & 0.50 & 0.71 \\
20050815 & 0.71 & 0.52 & 0.73 \\
20050822 & 0.62 & 0.43 & $\mathbf{0 . 6 6}$ \\
20050829 & 0.66 & 0.43 & $\mathbf{0 . 7 4}$ \\
\hline
\end{tabular}

Bold $=$ AMSR-E+QS has higher accuracy (statistically significant)

reduction in accuracy compared to classifications using any subset of the 10 bands. With a reduced number of bands, there are more cases of significant increases in accuracy due to using the full set of bands. Table $\mathrm{V}$ indicates that the data is not suffering from the "curse of dimensionality" [38], which refers to the problem where increasing the number of features (in this case bands) used in classification results in lower classification accuracy. The classification using all 10 available bands results in improvements over the smaller subsets or does not make a statistically significant difference. Therefore, the full set of bands should be used to take maximum advantage of all the information available. This is important because feature selection does not always choose the QuikSCAT band even though it offers additional information, as shown earlier by the dashes in Table II.

Table VI shows the order in which bands from the AMSR$\mathrm{E}+$ QuikSCAT data set were chosen by the SFS algorithm. This shows the relative ranking of the bands in terms of maximizing the minimum class separability for each date. The QuikSCAT H-pol band is frequently chosen as one of the first 3 bands which shows that it provides good separability. The band scoring portion of the table takes the band order and calculates a rough score that allows for ranking of the bands over all dates. It shows that, overall, QuikSCAT-H is a favoured band by the SFS algorithm to maximize class separability. The second best is the $36-\mathrm{H}$ band. Comparatively, the QuikSCAT-V band is not as favourable to maximizing class separability. Although these rankings show that some bands offer more class separability, they are not necessarily indicative of classifier performance. For example, the QuikSCAT band was chosen as the first band from the combined data set for 20040606 and 20041004 and yet it was shown earlier in Table II that this had a worse classifier performance than using the AMSR-E band that was chosen first using the AMSR-E alone data set. These indicate that feature selection can be wrong and provide further evidence that all the bands should be chosen to ensure that the full amount of information is used.

\section{Question 3: PCA data fusion}

The previous section has shown that increasing the number of bands used in classification does not result in any loss of classification accuracy. It also indicated that using an insufficient number of bands for classification results in poorer performance at a statistically significant level. This shows that useful information in all the bands is not fully captured using 


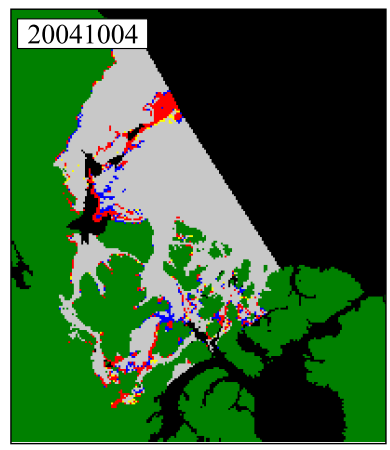

$1000 \mathrm{~km}$
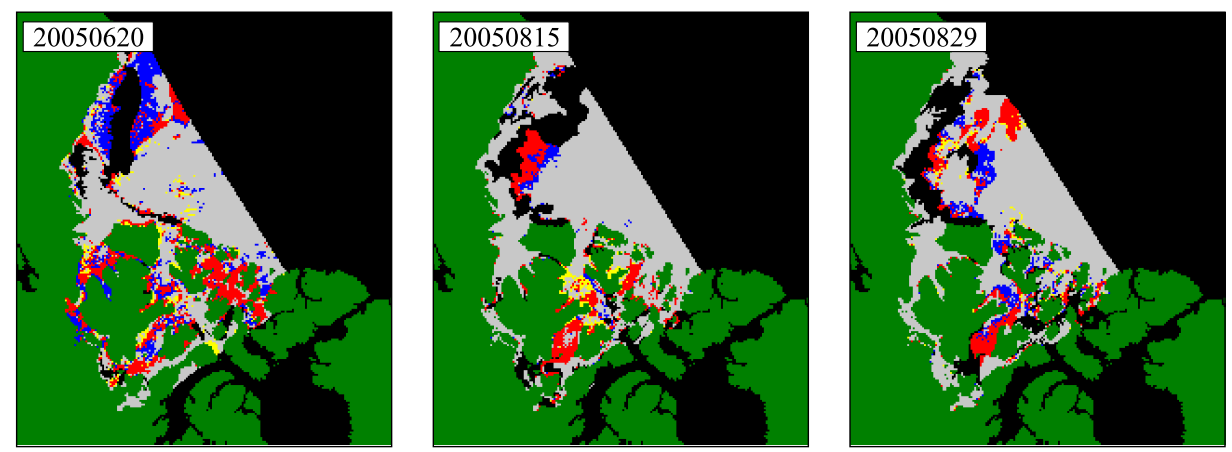

AMSR-E + QuikSCAT correct $\square$ AMSR-E correct $\square$ Land $\square$ No ground truth

(a) Spatial comparison.

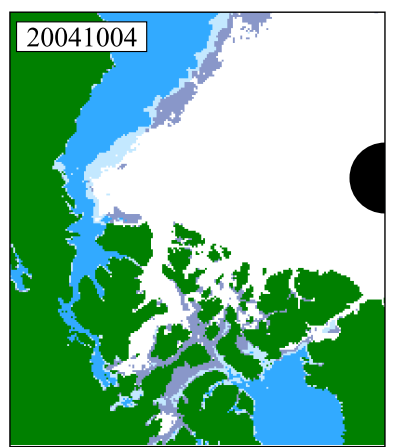

$1000 \mathrm{~km}$

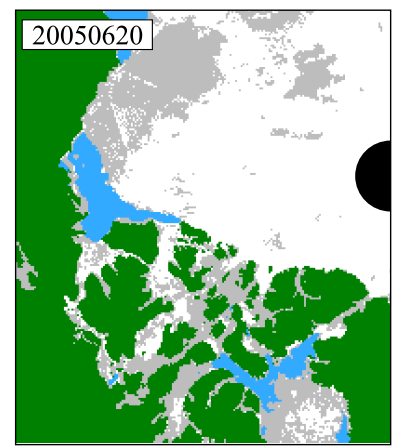

$\square$ Open Water $\square$ New Ice

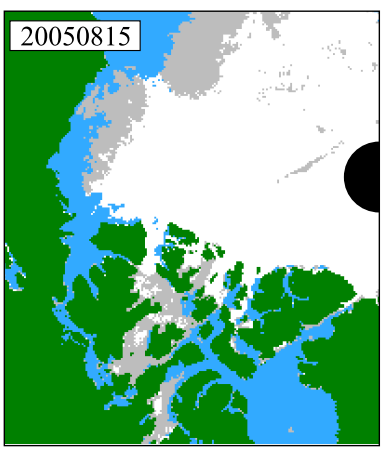

Young Ice $\square$ First Year Ice $\square$ Multiyear ice $\square$ Land

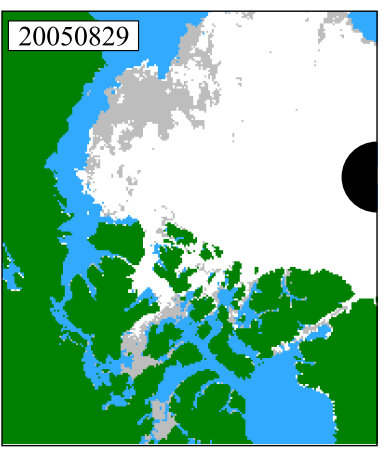

No pixel data

(b) Classification results using all 10 AMSR-E + QuikSCAT bands.

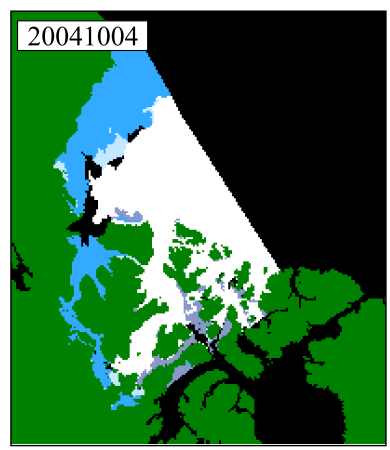

$1000 \mathrm{~km}$
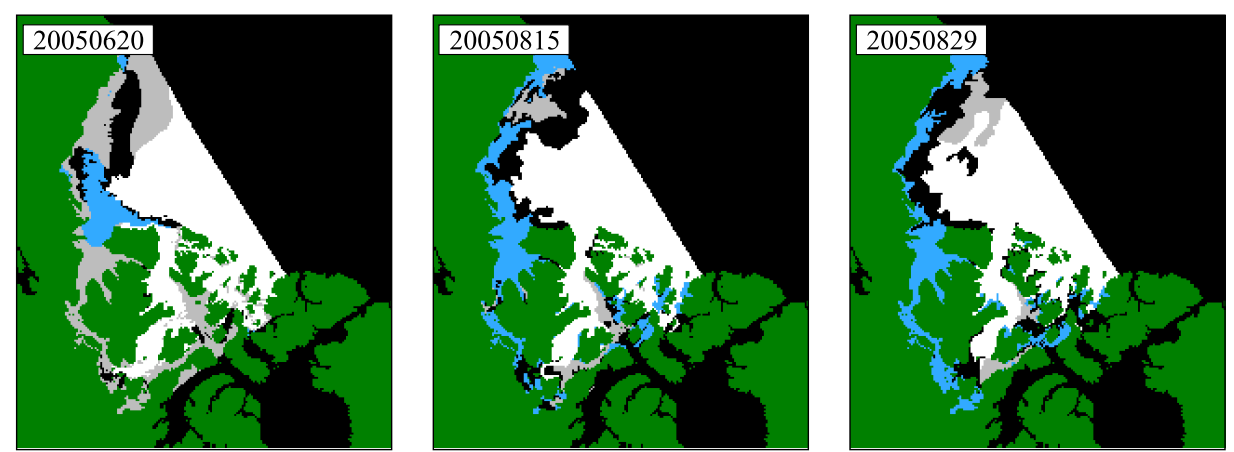

$\square$ Open Water $\square$ New Ice $\square$ Young Ice $\square$ First Year Ice $\square$ Multiyear ice $\square$ Land $\square$ No ground truth

(c) CIS ice charts.

Fig. 1. (a) A spatial comparison of accuracy between the 8 band AMSR-E only and the 10 band AMSR-E + QuikSCAT data set for 4 dates. Colours at each pixel indicate how each data set performed when classifying that pixel. Although the combined data set improves classification overall (as indicated by the abundance of blue pixels), there are cases such as for 20050815 where certain portions of the image (yellow) are more accurately classified by the AMSR-E alone data set. (b) Classification results with the 10 band combined data for the same 4 dates. (c) Canadian Ice Service ice charts.

subsets of the original bands. In this section, PCA data fusion is investigated to determine if it can extract useful information from all the bands into a representation with fewer dimensions. Previous research on multisensor sea ice classification has used PCA data fusion in this manner [18] but it remains to be seen whether the same technique will work for the AMSR-E + QuikSCAT data set.

The PCA transform was applied to the combined AMSR-E + QuikSCAT data set. Table VII shows the Z-values which compare the classification results which use the principal component (PC) bands and classification results that simply took subsets of the original bands. Each column indicates the number of bands used for both the PCA transformed data and the original data. For the PCA transformed data, the specified number of $\mathrm{PC}$ bands corresponding to the largest eigenvalues (and hence accounting for the greatest variance information) were kept. For the original data, SFS was used to select subsets of the specified size. The results show that using PCA for dimensionality reduction does not result in any clear advantage over using SFS alone. In some cases, PCA provides better results but there are also a large number of statistically significant decreases in classification performance as compared to using the original bands. The majority of cases when using only a single principal component shows 
TABLE IV

PRODUCER'S CLASSIFICATION ACCURACY, WHICH INDICATES THE PERCENTAGE OF GROUND TRUTH TESTING SAMPLES OF EACH INDIVIDUAL ICE CLASS THAT WAS CORRECTLY IDENTIFIED, FOR EACH DATE USING THE FULL 8 BAND AMSR-E (A) DATA SET AND USING THE COMBINED 10-BAND AMSR-E + QUIKSCAT (A+QS) DATA SET.

\begin{tabular}{|c|c|c|c|c|c|c|}
\hline & & \multicolumn{5}{|c|}{ Accuracy (\%) } \\
\hline Dates & Data Set & New & Young & $\mathrm{FY}$ & MY & Water \\
\hline \multirow[t]{2}{*}{20040906} & $\mathrm{~A}$ & - & - & 79 & 91 & 96 \\
\hline & $\mathrm{A}+\mathrm{QS}$ & - & - & 74 & 92 & 96 \\
\hline \multirow[t]{2}{*}{20041004} & A & 70 & 87 & - & 85 & 92 \\
\hline & $\mathrm{A}+\mathrm{QS}$ & 74 & 88 & - & 89 & 93 \\
\hline \multirow[t]{2}{*}{20041025} & $\mathrm{~A}$ & 72 & 60 & 89 & 78 & 96 \\
\hline & $\mathrm{A}+\mathrm{QS}$ & 75 & 67 & 91 & 78 & 96 \\
\hline \multirow[t]{2}{*}{20041108} & $\mathrm{~A}$ & - & 78 & 82 & 80 & - \\
\hline & $\mathrm{A}+\mathrm{QS}$ & - & 83 & 81 & 85 & - \\
\hline \multirow{2}{*}{20050301} & A & - & - & 94 & 95 & - \\
\hline & $\mathrm{A}+\mathrm{QS}$ & - & - & 94 & 95 & - \\
\hline \multirow{2}{*}{20050601} & A & - & - & 85 & 73 & 95 \\
\hline & $\mathrm{A}+\mathrm{QS}$ & - & - & 86 & 76 & 95 \\
\hline \multirow[t]{2}{*}{20050613} & $\mathrm{~A}$ & - & - & 69 & 77 & 97 \\
\hline & $\mathrm{A}+\mathrm{QS}$ & - & - & 77 & 79 & 97 \\
\hline \multirow[t]{2}{*}{20050620} & $\mathrm{~A}$ & - & - & 51 & 71 & 95 \\
\hline & $\mathrm{A}+\mathrm{QS}$ & - & - & 76 & 74 & 95 \\
\hline \multirow[t]{2}{*}{20050704} & $\mathrm{~A}$ & - & - & 53 & 84 & 97 \\
\hline & $\mathrm{A}+\mathrm{QS}$ & - & - & 65 & 83 & 97 \\
\hline \multirow[t]{2}{*}{20050711} & $\mathrm{~A}$ & - & - & 57 & 88 & 93 \\
\hline & $\mathrm{A}+\mathrm{QS}$ & - & - & 70 & 87 & 94 \\
\hline \multirow[t]{2}{*}{20050718} & $\mathrm{~A}$ & - & - & 85 & 84 & 95 \\
\hline & $\mathrm{A}+\mathrm{QS}$ & - & - & 86 & 84 & 94 \\
\hline \multirow[t]{2}{*}{20050725} & $\mathrm{~A}$ & - & - & 74 & 84 & 94 \\
\hline & $\mathrm{A}+\mathrm{QS}$ & - & - & 78 & 82 & 94 \\
\hline \multirow[t]{2}{*}{20050801} & $\mathrm{~A}$ & - & - & 68 & 84 & 96 \\
\hline & $\mathrm{A}+\mathrm{QS}$ & - & - & 70 & 84 & 95 \\
\hline \multirow[t]{2}{*}{20050808} & $\mathrm{~A}$ & - & - & 85 & 79 & 97 \\
\hline & $\mathrm{A}+\mathrm{QS}$ & - & - & 90 & 81 & 94 \\
\hline \multirow[t]{2}{*}{20050815} & A & - & - & 77 & 80 & 96 \\
\hline & $\mathrm{A}+\mathrm{QS}$ & - & - & 87 & 80 & 96 \\
\hline \multirow[t]{2}{*}{20050822} & $\mathrm{~A}$ & - & - & 88 & 67 & 96 \\
\hline & $\mathrm{A}+\mathrm{QS}$ & - & - & 91 & 71 & 96 \\
\hline \multirow[t]{2}{*}{20050829} & A & - & - & 79 & 74 & 95 \\
\hline & $\mathrm{A}+\mathrm{QS}$ & - & - & 87 & 81 & 96 \\
\hline
\end{tabular}

Bold = AMSR-E + QuikSCAT has higher accuracy. Italic $=$ AMSR-E has higher accuracy

Plain $=$ No difference.
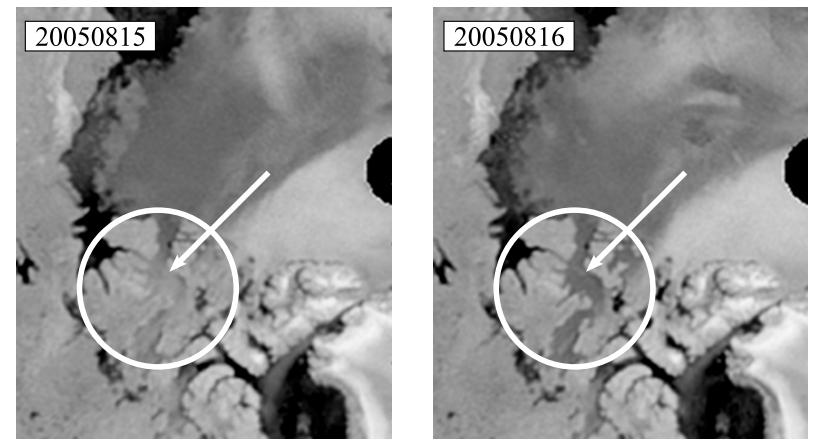

Fig. 2. An example of a transient weather effect in a QuikSCAT image. The QuikSCAT image for the day immediately after 20050815 shows a marked change in backscatter intensity for this location, corresponding to the location (indicated by the arrows, also see the comparison in Figure 1(a) for 20080815) where the classification using AMSR-E + QuikSCAT was incorrect while the classification using AMSR-E alone was correct. This effect appears to be responsible for the poorer performance of the combined data set at that particular location.

a decrease in performance. The first principal component, rather than being a useful combination of all the original bands, is a poor band to use when compared to the best single band chosen by SFS. As the number of bands used increases, PCA and SFS results approach each other so that there are few significant differences in classification accuracy. This experiment shows that PCA is not an advantageous data fusion technique for these data.

\section{Question 4: Reliability of training data over time}

In the previous experiments, each date was trained independently. In this section, training is done with all samples from one date and applied to classify other dates in 2004 to 2005 , with one date being classified at a time. The test is repeated by training with each date that has sufficient training samples. This experiment reveals the applicability of the training data over time. The classification results are binned by the absolute number of days between the date of the training data and the date being classified ( $\Delta$ Days). The bin size is 15 days. Figure 3 shows the mean $\kappa$ calculated from all the classification results in each bin as a function of $\Delta$ Days. Error bars indicate the standard deviation of the $\kappa$ values in each bin. As expected, accuracy decreases with increasing $\Delta$ Days. The AMSR-E + QuikSCAT data set has higher average $\kappa$ than the AMSR$\mathrm{E}$ alone data set for larger $\Delta$ Days, suggesting more time invariance but with large $\Delta$ Days, the $\kappa$ values have a higher spread and there are negative $\kappa$ values. Negative $\kappa$ indicate that the results are biased to be worse than even random assignment and are clearly unacceptable. Overall, the QuikSCAT only data set seems to have the most time invariance as indicated by higher average $\kappa$ but it is not entirely consistent and there is a high spread. Additionally, the largest average $\kappa$ obtained over all $\triangle$ Days for the QuikSCAT only data set is not any higher than the best values from the combined data set which is obtained within 30 days of the training date. This test shows that training data within 30 days of the date being classified is acceptable, an important consideration if a database of training data is to be created for automated classification.

\section{CONClusion}

This work has shown that the combined data set gives statistically better results than either AMSR-E or QuikSCAT data alone for sea ice classification. The data appear to be complementary, providing classification accuracy improvements in all ice types. Using the full 10 bands of AMSR-E + QuikSCAT is recommended since this uses all of the available data without suffering from dimensionality problems. The use of PCA for data fusion is not motivated by the test results as it does not offer any consistent and statistically significant advantage. Training data for this data set appear to be valid for only about a month, so training databases will have to be designed accordingly. Although the findings here are strictly for the western Arctic area, preliminary tests that consider the entire Arctic show similar results. This will be investigated in more detail.

Future work should look at improving the classification accuracy in an absolute sense, since there are instances where even the combined data set is classified incorrectly. This improvement may be obtained by designing a different classifier 
TABLE V

Z-VALUES COMPARING THE CLASSIFICATION RESULTS USING THE FULL SET OF 10 AMSR-E + QS BANDS WITH CLASSIFICATIONS DONE USING SUBSETS OF THE AMSR-E + QS BANDS OF THE SPECIFIED SIZES.

\begin{tabular}{|c|r|r|r|r|r|r|r|r|r|}
\hline & \multicolumn{10}{|c|}{ Number of Bands Used For Classification } \\
\hline Dates & 1 & 2 & 3 & 4 & 5 & 6 & 7 & 8 & 9 \\
\hline 20040906 & $\mathbf{5 . 5 4}$ & 1.60 & 1.22 & 1.06 & 0.54 & -0.03 & 0.74 & -0.29 & -0.09 \\
20041004 & $\mathbf{1 3 . 3 6}$ & $\mathbf{6 . 0 8}$ & $\mathbf{5 . 8 1}$ & 1.06 & 1.29 & 1.09 & 0.67 & -0.54 & -0.91 \\
20041025 & $\mathbf{3 . 3 9}$ & $\mathbf{4 . 6 1}$ & $\mathbf{4 . 0 4}$ & $\mathbf{3 . 2 8}$ & 1.60 & 1.71 & 0.76 & 0.75 & 0.25 \\
2004108 & $\mathbf{1 2 . 9 1}$ & $\mathbf{5 . 7 7}$ & $\mathbf{2 . 9 9}$ & $\mathbf{3 . 9 2}$ & $\mathbf{4 . 3 3}$ & $\mathbf{5 . 1 2}$ & $\mathbf{2 . 1 9}$ & 1.90 & 1.15 \\
20050301 & -0.39 & 0.31 & -0.09 & 0.36 & 0.40 & 0.00 & -0.23 & 0.18 & 0.05 \\
20050601 & $\mathbf{1 2 . 6 0}$ & $\mathbf{1 0 . 0 9}$ & $\mathbf{8 . 1 4}$ & $\mathbf{7 . 3 3}$ & $\mathbf{6 . 3 5}$ & $\mathbf{5 . 7 4}$ & $\mathbf{5 . 0 4}$ & $\mathbf{2 . 6 3}$ & 0.92 \\
20050613 & $\mathbf{2 4 . 0 1}$ & $\mathbf{1 1 . 5 1}$ & $\mathbf{9 . 0 8}$ & $\mathbf{6 . 9 1}$ & $\mathbf{3 . 8 0}$ & $\mathbf{2 . 5 4}$ & 1.15 & 0.74 & -0.22 \\
20050620 & $\mathbf{2 5 . 0 7}$ & $\mathbf{1 0 . 1 6}$ & $\mathbf{6 . 5 8}$ & $\mathbf{5 . 2 1}$ & $\mathbf{2 . 8 4}$ & $\mathbf{3 . 6 3}$ & 0.98 & 1.01 & 0.25 \\
20050704 & $\mathbf{1 0 . 5 2}$ & $\mathbf{6 . 5 6}$ & $\mathbf{7 . 4 8}$ & $\mathbf{5 . 2 4}$ & $\mathbf{4 . 3 2}$ & $\mathbf{4 . 1 2}$ & $\mathbf{1 . 9 6}$ & 1.34 & 0.42 \\
20050711 & $\mathbf{1 1 . 2 6}$ & $\mathbf{8 . 6 7}$ & $\mathbf{6 . 2 5}$ & $\mathbf{3 . 6 3}$ & 1.21 & 1.09 & 0.84 & 1.16 & 0.93 \\
20050718 & $\mathbf{9 . 6 5}$ & $\mathbf{6 . 9 6}$ & $\mathbf{5 . 1 4}$ & $\mathbf{3 . 0 7}$ & $\mathbf{4 . 3 1}$ & $\mathbf{3 . 3 8}$ & 1.43 & 0.43 & 0.22 \\
20050725 & $\mathbf{7 . 9 4}$ & $\mathbf{9 . 1 9}$ & $\mathbf{8 . 7 3}$ & $\mathbf{6 . 0 3}$ & $\mathbf{3 . 2 2}$ & 0.85 & 0.15 & -0.06 & 0.05 \\
20050801 & $\mathbf{2 . 8 5}$ & $\mathbf{6 . 9 5}$ & $\mathbf{5 . 6 6}$ & $\mathbf{4 . 4 3}$ & $\mathbf{2 . 3 0}$ & 1.46 & 1.49 & 0.73 & 0.68 \\
20050808 & $\mathbf{8 . 2 6}$ & $\mathbf{9 . 6 2}$ & $\mathbf{4 . 8 8}$ & $\mathbf{2 . 3 2}$ & $\mathbf{2 . 1 0}$ & 0.87 & 1.13 & -0.24 & -0.28 \\
20050815 & $\mathbf{3 . 4 1}$ & $\mathbf{7 . 2 1}$ & $\mathbf{3 . 6 7}$ & $\mathbf{3 . 0 5}$ & $\mathbf{2 . 2 9}$ & $\mathbf{1 . 9 9}$ & 1.24 & -0.24 & 0.21 \\
20050822 & $\mathbf{2 4 . 0 2}$ & $\mathbf{1 3 . 3 1}$ & $\mathbf{9 . 4 5}$ & $\mathbf{6 . 4 0}$ & $\mathbf{4 . 0 5}$ & $\mathbf{4 . 2 3}$ & $\mathbf{2 . 8 4}$ & 1.35 & 0.40 \\
20050829 & $\mathbf{2 4 . 6 2}$ & $\mathbf{1 2 . 9 6}$ & $\mathbf{1 5 . 4 6}$ & $\mathbf{1 0 . 3 0}$ & $\mathbf{5 . 9 0}$ & $\mathbf{4 . 8 6}$ & $\mathbf{4 . 0 0}$ & 0.38 & 0.12 \\
\hline
\end{tabular}

Bold $=$ Full set of bands has higher accuracy; Plain $=$ Not significant.

TABLE VI

THE ORDER IN WHICH BANDS FROM THE COMBINED AMSR-E + QUIKSCAT DATA SET WERE CHOSEN BY THE SFS ALGORITHM FOR EACH DATE ARE SHOWN. THE SCORE OF EACH BAND USING THE BAND ORDER INFORMATION FOR ALL DATES IS ALSO SHOWN, INDICATING THAT QUIKSCAT-H IS THE TOP BAND ACCORDING TO CLASS SEPARABILITY.

\begin{tabular}{|c|r|r|r|r|r|r|r|r|r|r|}
\hline & \multicolumn{10}{|c|}{ Band Order } \\
\hline Date & 1 & 2 & 3 & 4 & 5 & 6 & 7 & 8 & 9 & 10 \\
\hline 20040906 & QS-H & $36-V$ & $23-H$ & $18-\mathrm{H}$ & $18-\mathrm{V}$ & $36-\mathrm{H}$ & $89-\mathrm{H}$ & $89-\mathrm{V}$ & $23-\mathrm{V}$ & QS-V \\
20041004 & QS-H & $18-\mathrm{V}$ & $36-\mathrm{V}$ & $36-\mathrm{H}$ & $89-\mathrm{H}$ & $23-\mathrm{H}$ & $23-\mathrm{V}$ & QS-V & $89-\mathrm{V}$ & $18-\mathrm{H}$ \\
20041025 & QS-H & $36-\mathrm{V}$ & $36-\mathrm{H}$ & $89-\mathrm{V}$ & $18-\mathrm{H}$ & $23-\mathrm{V}$ & $89-\mathrm{H}$ & QS-V & $18-\mathrm{V}$ & $23-\mathrm{H}$ \\
20041108 & $89-\mathrm{V}$ & $36-\mathrm{H}$ & $36-\mathrm{V}$ & $18-\mathrm{V}$ & $23-\mathrm{V}$ & $23-\mathrm{H}$ & QS-H & $18-\mathrm{H}$ & $89-\mathrm{H}$ & QS-V \\
20050301 & $23-\mathrm{V}$ & QS-V & $89-\mathrm{H}$ & $18-\mathrm{V}$ & $18-\mathrm{H}$ & $36-\mathrm{V}$ & $89-\mathrm{V}$ & $36-\mathrm{H}$ & QS-H & $23-\mathrm{H}$ \\
20050601 & QS-H & $23-\mathrm{V}$ & $18-\mathrm{V}$ & $36-\mathrm{V}$ & $23-\mathrm{H}$ & $36-\mathrm{H}$ & $89-\mathrm{H}$ & QS-V & $18-\mathrm{H}$ & $89-\mathrm{V}$ \\
20050613 & $89-\mathrm{V}$ & QS-H & $89-\mathrm{H}$ & $18-\mathrm{V}$ & $23-\mathrm{V}$ & $36-\mathrm{V}$ & QS-V & $36-\mathrm{H}$ & $18-\mathrm{H}$ & $23-\mathrm{H}$ \\
20050620 & $89-\mathrm{V}$ & QS-H & $23-\mathrm{H}$ & $36-\mathrm{V}$ & $18-\mathrm{V}$ & $89-\mathrm{H}$ & $18-\mathrm{H}$ & $36-\mathrm{H}$ & QS-V & $23-\mathrm{V}$ \\
20050704 & QS-H & $18-\mathrm{H}$ & $23-\mathrm{H}$ & $36-\mathrm{H}$ & $89-\mathrm{V}$ & $36-\mathrm{V}$ & QS-V & $18-\mathrm{V}$ & $23-\mathrm{V}$ & $89-\mathrm{H}$ \\
20050711 & $36-\mathrm{H}$ & QS-H & $23-\mathrm{V}$ & QS-V & $18-\mathrm{H}$ & $23-\mathrm{H}$ & $89-\mathrm{H}$ & $36-\mathrm{V}$ & $18-\mathrm{V}$ & $89-\mathrm{V}$ \\
20050718 & $36-\mathrm{H}$ & $23-\mathrm{V}$ & $23-\mathrm{H}$ & $18-\mathrm{H}$ & $36-\mathrm{V}$ & QS-H & $89-\mathrm{H}$ & $89-\mathrm{V}$ & QS-V & $18-\mathrm{V}$ \\
20050725 & $18-\mathrm{V}$ & $18-\mathrm{H}$ & QS-H & $36-\mathrm{H}$ & $23-\mathrm{H}$ & $89-\mathrm{V}$ & $89-\mathrm{H}$ & $36-\mathrm{V}$ & QS-V & $23-\mathrm{V}$ \\
20050801 & $36-\mathrm{H}$ & $89-\mathrm{V}$ & QS-H & $23-\mathrm{H}$ & $18-\mathrm{V}$ & $23-\mathrm{V}$ & $36-\mathrm{V}$ & $89-\mathrm{H}$ & QS-V & $18-\mathrm{H}$ \\
20050808 & $36-\mathrm{H}$ & $36-\mathrm{V}$ & QS-H & $89-\mathrm{V}$ & $89-\mathrm{H}$ & $23-\mathrm{H}$ & $23-\mathrm{V}$ & $18-\mathrm{H}$ & $18-\mathrm{V}$ & QS-V \\
20050815 & $23-\mathrm{H}$ & $36-\mathrm{V}$ & QS-H & $23-\mathrm{V}$ & $89-\mathrm{H}$ & $36-\mathrm{H}$ & $89-\mathrm{V}$ & $18-\mathrm{H}$ & $18-\mathrm{V}$ & QS-V \\
20050822 & QS-V & $36-\mathrm{V}$ & $36-\mathrm{H}$ & $89-\mathrm{V}$ & $18-\mathrm{H}$ & $23-\mathrm{V}$ & $23-\mathrm{H}$ & $18-\mathrm{V}$ & QS-H & $89-\mathrm{H}$ \\
20050829 & $89-\mathrm{H}$ & $18-\mathrm{H}$ & $18-\mathrm{V}$ & QS-V & $89-\mathrm{V}$ & QS-H & $36-\mathrm{V}$ & $23-\mathrm{H}$ & $23-\mathrm{V}$ & $36-\mathrm{H}$ \\
\hline
\end{tabular}

Band Scoring Based on Order, Score $=\sum_{d} 11-\operatorname{BandOrder}($ Band, $d)$

\begin{tabular}{|c|r|r|r|r|r|r|r|r|r|r|}
\hline Band & $18 \mathrm{~V}$ & $18 \mathrm{H}$ & $23 \mathrm{~V}$ & $23 \mathrm{H}$ & $36 \mathrm{~V}$ & $36 \mathrm{H}$ & $89 \mathrm{~V}$ & $89 \mathrm{H}$ & $\mathrm{QSH}$ & QSV \\
\hline Score & 89 & 57 & 77 & 100 & 65 & 138 & 113 & 89 & 145 & 62 \\
\hline
\end{tabular}

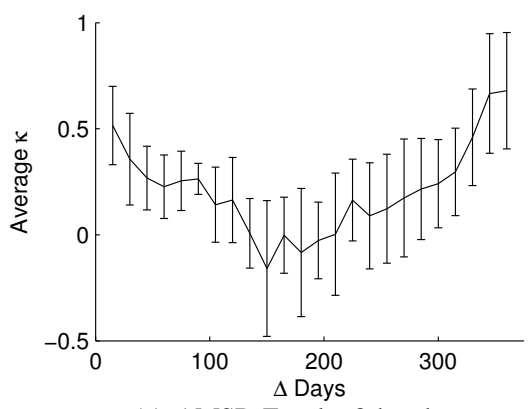

(a) AMSR-E only, 8 bands.

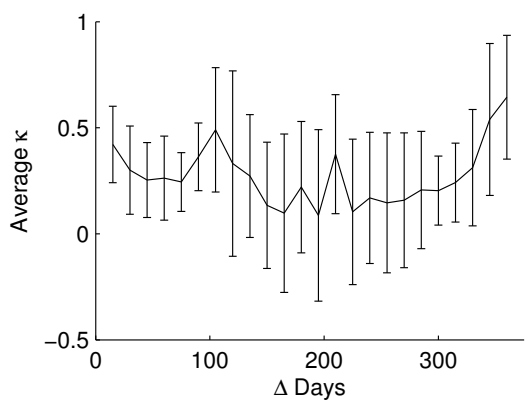

(b) QuikSCAT only, 2 bands.

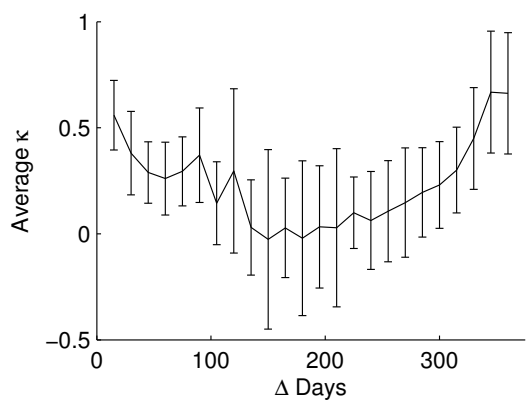

(c) AMSR-E and QuikSCAT, 10 bands.

Fig. 3. Average $\kappa$ obtained for classification results on dates that are $\Delta$ Days from training dates for the separate data sets as well as the combined data set. The average kappa indicate that classification is best for dates that are close to the training date or nearly one year away. Dates that are within 30 days of the training date seem to be classified well. 
TABLE VII

Z-VALUES COMPARING AMSR-E + QS WITH PCA DATA FUSION AGAINST USING THE ORIGINAL AMSR-E + QS BANDS. THE COLUMNS INDICATE THE NUMBER OF BANDS USED IN CLASSIFICATION FOR BOTH CASES.

\begin{tabular}{|c|r|r|r|r|r|r|r|r|r|}
\hline & \multicolumn{10}{|c|}{ Number of Bands Used For Classification } \\
\hline Dates & 1 & 2 & 3 & 4 & 5 & 6 & 7 & 8 & 9 \\
\hline 20040906 & $\mathbf{2 . 7 3}$ & -0.44 & -1.58 & -1.04 & -0.65 & -1.54 & 0.27 & -0.90 & 0.06 \\
20041004 & $\mathbf{7 . 4 8}$ & -0.70 & -0.69 & -5.59 & 0.02 & 1.80 & 1.74 & 0.86 & 0.13 \\
20041025 & -4.76 & $\mathbf{2 . 2 1}$ & $\mathbf{2 . 4 8}$ & 1.83 & -0.70 & -0.03 & -1.38 & -0.37 & 0.02 \\
20041108 & -15.71 & $\mathbf{6 . 0 6}$ & $\mathbf{5 . 2 9}$ & $\mathbf{5 . 5 7}$ & $\mathbf{5 . 1 3}$ & $\mathbf{5 . 4 4}$ & $\mathbf{2 . 5 0}$ & $\mathbf{2 . 2 5}$ & 1.59 \\
20050301 & -16.76 & 0.18 & -0.55 & -0.32 & 0.26 & 0.85 & 0.09 & 0.58 & 0.27 \\
20050601 & -13.16 & -2.01 & 0.72 & 0.53 & 1.56 & $\mathbf{2 . 2 1}$ & $\mathbf{2 . 3 9}$ & 1.94 & 1.28 \\
20050613 & -2.40 & -9.39 & 0.27 & -1.39 & -1.37 & -2.54 & -2.24 & -0.50 & -0.68 \\
20050620 & $\mathbf{5 . 7 0}$ & -2.66 & 0.51 & 0.42 & -1.11 & 0.09 & -1.89 & 0.85 & -0.10 \\
20050704 & -2.52 & -1.99 & -1.27 & -0.54 & 0.24 & 1.17 & -0.49 & 0.09 & -0.33 \\
20050711 & -3.95 & -1.75 & -1.29 & -0.64 & -0.43 & 0.00 & 0.00 & 0.04 & 0.38 \\
20050718 & -2.87 & -4.81 & -5.19 & -3.42 & -1.91 & -0.60 & 0.52 & -0.12 & -0.04 \\
20050725 & -2.02 & 0.59 & 1.32 & -0.78 & -0.53 & -2.09 & -0.30 & -0.20 & 0.01 \\
20050801 & -6.23 & 1.94 & -0.45 & -0.51 & -2.86 & -2.56 & -2.08 & -1.30 & -0.05 \\
20050808 & 0.17 & 1.41 & 1.94 & -0.69 & -0.67 & -1.84 & -0.91 & 0.06 & -0.34 \\
20050815 & -6.68 & $\mathbf{4 . 3 5}$ & -0.22 & 0.46 & -0.40 & -1.44 & -1.58 & -0.59 & -0.03 \\
20050822 & $\mathbf{6 . 0 1}$ & 1.86 & -0.88 & -0.97 & -2.06 & -0.55 & 1.26 & -0.21 & -0.66 \\
20050829 & $\mathbf{7 . 2 0}$ & -4.50 & $\mathbf{2 . 3 8}$ & -1.96 & -4.16 & -4.18 & -1.50 & 0.17 & 0.22 \\
\hline
\end{tabular}

Bold $=$ PCA has higher accuracy; Italic $=$ Original bands has higher accuracy Plain $=$ Not significant

or using another method of data fusion. The results presented in this study show that QuikSCAT provides additional information. The work that remains is how to make the best use of it.

\section{ACKNOWLEDGMENT}

The authors would like to thank Canadian Ice Service staff for data and advice. The helpful discussions and guidance provided by Roger De Abreu of CIS and Tom Agnew of Environment Canada must also be acknowledged. The Natural Sciences and Engineering Research Council of Canada and the Canadian Federal Government's International Polar Year are thanked for financially supporting this project.

AMSR-E data was obtained from the National Snow and Ice Data Center. QuikSCAT Data was obtained from the NASA sponsored Scatterometer Climate Record Pathfinder at Brigham Young University through the courtesy of David G. Long.

\section{REFERENCES}

[1] C. L. Parkinson and D. J. Cavalieri, "Arctic sea ice variability and trends, 1979 - 2006," J. Geophys. Res., vol. 113, no. C7, Jul. 2008.

[2] M. M. Holland, C. M. Bitz, and B. Tremblay, "Future abrupt reductions in the summer Arctic sea ice," Geophys. Res. Lett., vol. 33, no. L23503, Dec. 2006.

[3] J. Stroeve, M. M. Holland, W. Meier, T. Scambos, and M. Serreze, "Arctic sea ice decline: Faster than forecast," Geophys. Res. Lett., vol. 34, no. L09501, May 2007.

[4] S. V. Nghiem, I. G. Rigor, D. K. Perovich, P. Clemente-Colón, J. W. Weatherly, and G. Neumann, "Rapid reduction of Arctic perennial sea ice," Geophys. Res. Lett., vol. 34, no. L19504, Oct. 2007.

[5] R. De Abreu, K. Wilson, M. Arkett, and D. Langlois, "Evaluating the use of QuikSCAT data for operational sea ice monitoring," in Proc. Int'l Geosci. and Remote Sensing Symposium, vol. 5, Toronto, Canada, Jun. 2002, pp. 3032-3033.

[6] H. S. Anderson and D. G. Long, "Sea ice mapping method for SeaWinds," IEEE Trans. Geosci. Remote Sens., vol. 43, no. 3, pp. 647-657, Mar. 2005.

[7] Q. P. Remund and D. G. Long, "Sea ice extent mapping using Ku-band scatterometer data," J. Geophys. Res., vol. 105, no. C5, pp. $11515-$ 11527 , May 1999.
[8] _ , "Large-scale inverse Ku-band backscatter modeling of sea ice," IEEE Trans. Geosci. Remote Sens., vol. 41, no. 8, pp. 1821-1832, Aug. 2003.

[9] S. V. Nghiem, Y. Chao, G. Neumann, P. Li, D. K. Perovich, T. Street, and P. Clemente-Colón, "Depletion of perennial sea ice in the East Arctic Ocean," Geophys. Res. Lett., vol. 33, no. L17501, Sep. 2006.

[10] J. Haarpaintner, R. T. Tonboe, D. G. Long, and M. L. VanWoert, "Automatic detection and validity of the sea ice edge: An application of enhanced resolution QuikSCAT/SeaWinds data," IEEE Trans. Geosci. Remote Sens., vol. 42, no. 7, pp. 1433-1443, Jul. 2004.

[11] J. Haarpaintner and G. Spreen, "Use of enhanced-resolution QuikSCAT/SeaWinds data for operational ice services and climate research: sea ice edge, type, concentration, and drift," IEEE Trans. Geosci. Remote Sens., vol. 45, no. 10, pp. 3131-3137, Oct. 2007.

[12] S. Howell, J. J. Yackel, R. A. De Abreu, T. Geldsetzer, and C. Breneman, "On the utility of SeaWinds/QuikSCAT for the estimation of the thermodynamic state of first-year sea ice," IEEE Trans. Geosci. Remote Sens., vol. 43, no. 6, pp. 1338-1350, Jun. 2005.

[13] S. Howell, A. Tivy, J. J. Yackel, B. G. T. Else, and C. R. Duguay, "Changing sea ice melt parameters in the Canadian Arctic Archipelago: Implications for the future presence of multiyear ice," J. Geophys. Res., vol. 113, no. C09030, Sep. 2008.

[14] J. Haarpaintner, "Arctic-wide operational sea ice drift from enhanced resolution QuikScat/SeaWinds scatterometry and its validation," IEEE Trans. Geosci. Remote Sens., vol. 44, no. 1, pp. 102-107, Jan. 2006.

[15] M. Wensnahan, G. Maykut, T. Grenfell, and D. Winebrenner, "Passive microwave remote sensing of thin ice using principal component analysis," J. Geophys. Res., vol. 98, no. C7, pp. 12453-12 468, Jul. 1993.

[16] J. Comiso, D. Cavalieri, and T. Markus, "Sea ice concentration, ice temperature, and snow depth using AMSR-E data," IEEE Trans. Geosci. Remote Sens., vol. 41, no. 2, pp. 243-252, Feb. 2003.

[17] H. Lee and H. Han, "Evaluation of SSM/I and AMSR-E sea ice concentrations in the Antarctic spring using KOMPSAT-1 EOC images," IEEE Trans. Geosci. Remote Sens., vol. 46, no. 7, pp. 1905-1912, Jul. 2008.

[18] Q. P. Remund, D. G. Long, and M. R. Drinkwater, "An iterative approach to multisensor sea ice classification," IEEE Trans. Geosci. Remote Sens., vol. 38 , no. 4, pp. 1843-1856, Jul. 2000.

[19] R. Tonboe and L. Toudal, "Classification of new-ice in the Greenland Sea using satellite SSM/I radiometer and SeaWinds scatterometer data and comparison with ice model," Rem. Sens. Env., vol. 97, no. 3, pp. 277-287, Aug. 2005.

[20] N. P. Walker, K. C. Partington, M. L. V. Woert, and T. L. T. Street, "Arctic sea ice type and concentration mapping using passive and active microwave sensors," IEEE Trans. Geosci. Remote Sens., vol. 44, no. 12, pp. 3574-3584, Dec. 2006.

[21] T. Kawanishi, T. Sezai, Y. Ito, K. Imaoka, T. Takeshima, Y. Ishido, A. Shibata, M. Miura, H. Inahata, and R. W. Spencer, "The Advanced Microwave Scanning Radiometer for the Earth Observing System 
(AMSR-E), NASDA's contribution to the EOS for global energy and water cycle studies," IEEE Trans. Geosci. Remote Sens., vol. 41, no. 2, pp. 184-194, Feb. 2003.

[22] C. L. Parkinson, "Aqua: An earth-observing satellite mission to examine water and other climate variables," IEEE Trans. Geosci. Remote Sens. vol. 41 , no. 2 , pp. 173-183, Feb. 2003.

[23] D. Cavalieri and J. Comiso, AMSR-E/Aqua Daily L3 $12.5 \mathrm{~km} \mathrm{Tb,} \mathrm{Sea}$ Ice Conc, \& Snow Depth Polar Grids V001, Sept. 2004 to Aug. 2005. Boulder, CO: National Snow and Ice Data Center, 2004, digital media.

[24] D. Long and B. Hicks, "Standard BYU QuikSCAT/SeaWinds land/ice image products," Brigham Young University, Report Provo, Utah, 2005.

[25] D. S. Early and D. G. Long, "Image reconstruction and enhanced resolution imaging from irregular samples," IEEE Trans. Geosci. Remote Sens., vol. 39, no. 2, pp. 291-302, Feb. 2001.

[26] D. G. Long, P. J. Hardin, and P. T. Whitling, "Resolution enhancement of spaceborne scatterometer data," IEEE Trans. Geosci. Remote Sens. vol. 31, no. 3, pp. 700-715, May 1993.

[27] Canadian Ice Service Archive Documentation Series. (2006) Regional charts: History, accuracy, and caveats. [Online]. Available: http://ice.ec.gc.ca/IA DOC/cisads no 001 e.pdf

[28] T. Agnew and S. Howell, "The use of operational ice charts for evaluating passive microwave ice concentration data," Atmosphere-Ocean, vol. 41, no. 4, pp. 317-331, Dec. 2003.

[29] D. J. Cavalieri, C. L. Parkinson, P. Gloersen, J. C. Comiso, and H. J. Zwally, "Deriving long-term time series of sea ice cover from satellite passive-microwave multisensor data sets," J. Geophys. Res., vol. 104, no. C7, pp. 15 803-15 814, Jul. 1999.

[30] P. Swain, "Fundamentals of pattern recognition in remote sensing," in Remote Sensing: The Quantitative Approach, P. H. Swain and S. M. Davis, Eds. New York: McGraw-Hill, 1978, pp. 136-187.

[31] R. Duda, P. Hart, and D. Stork, Pattern Classification, 2nd ed. New York: Wiley, 2001.

[32] A. Jain and D. Zongker, "Feature selection: evaluation, application, and small sample performance," IEEE Trans. Pattern Anal. Mach. Intell., vol. 19, no. 2, pp. 153-158, Feb. 1997.

[33] A. W. Whitney, "A direct method of nonparametric measurement selection," IEEE Trans. Comput., vol. C-20, no. 9, pp. 1100-1103, Sep. 1971.

[34] P. Pudil, J. Novovičová, and J. Kittler, "Floating search methods in feature selection," Pattern Recognition Letters, vol. 15, no. 11, pp. 11191125, Nov. 1994

[35] R. Schowengerdt, Remote Sensing: Models and Methods for Image Processing., 2nd ed. San Diego: Academic Press, 1997.

[36] T. Bishop, S. Fienberg, and P. Holland, Discrete Multivariate Analysis - Theory and Practice. Cambridge: MIT Press, 1975.

[37] R. G. Congalton, R. G. Oderwald, and R. A. Mead, "Assessing Landsat classification accuracy using discrete multivariate analysis statistical techniques," Photogram. Eng. Remote Sens., vol. 49, no. 12, pp. 16711678, Dec. 1983.

[38] A. Jain and B. Chandrasekaran, "Dimensionality and sample size considerations in pattern recognition practice," in Handbook of Statistics, P. Krishnaiah and L. Kanal, Eds. Amsterdam: North-Holland, 1982, vol. 2, pp. 835-855.

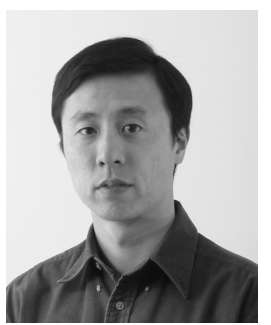

Peter Yu received the B.A.Sc. degree in Systems Design Engineering from the University of Waterloo (Waterloo, Ontario, Canada) in 2007, where he is currently a candidate for the M.A.Sc. degree in the same department. His current research topic is computer aided interpretation of sea ice images from synthetic aperture radar. His research interests include image processing, pattern recognition and remote sensing.

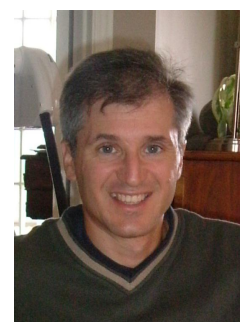

David A. Clausi earned his B.A.Sc. (1990), M.A.Sc. (1992), and Ph.D. (1996) in Systems Design Engineering at the University of Waterloo (Waterloo, Ontario, Canada). After completing his doctorate, Prof. Clausi worked in the medical imaging field at Mitra Imaging Inc. (Waterloo). He started his academic career in 1997 as an Assistant Professor in Geomatics Engineering at the University of Calgary, Alberta, Canada. In 1999, he returned to his alma mater and is now an Associate Professor specializing in the fields of Intelligent Systems as well as Societal and Environmental Systems. Prof. Clausi is an active interdisciplinary and multidisciplinary researcher. He has an extensive publication record, publishing refereed journal and conference papers in the diverse fields of remote sensing, computer vision, algorithm design, finite element modeling, and biomechanics. His primary research interest is the automated interpretation of synthetic aperture radar (SAR) sea ice imagery, in support of operational activities. His research efforts have led to successful commercial implementations. He has received numerous scholarships, paper awards, and two Teaching Excellence Awards

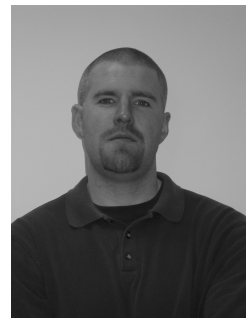

Stephen E. L. Howell received the B.Sc. (Hons.) degree in physical geography from York University, Toronto, ON, Canada, in 2000, and the M.G.I.S and $\mathrm{Ph} . \mathrm{D}$. degrees from the University of Calgary, Calgary, AB, Canada, in 2003 and 2007, respectively. He is currently a Post-Doctoral Fellow in the Department of Geography at the University of Waterloo, Waterloo, ON, Canada. 